\title{
OPEN Enhanced energy density of PVDF-based nanocomposites via a core-shell strategy
}

\author{
JingJing $\mathrm{Xu}^{1,2}$, Chao $\mathrm{Fu}^{1}$, Huiying $\mathrm{Chu}^{1,2}$, Xianyou $\mathrm{Wu}^{1,2}$, Zhongyang $\operatorname{Tan}^{1}$, Jing $\mathrm{Oian}^{1}$, \\ Weiyan $\mathrm{Li}^{1,2}$, Zhongqian Song ${ }^{1}$, Xianghai $\operatorname{Ran}^{1,2 \varpi}$ \& Wei Nie ${ }^{1,2 \llbracket}$
}

In recent years, high energy density polymer capacitors have attracted a lot of scientific interest due to their potential applications in advanced power systems and electronic devices. Here, core-shell structured $\mathrm{TiO}_{2} @ \mathrm{SrTiO}_{3} @$ polydamine nanowires $\left(\mathrm{TiO}_{2} @ \mathrm{SrTiO}_{3} @ \mathrm{PDA} \mathrm{NWs}\right.$ were synthesized via a combination of surface conversion reaction and in-situ polymerization method, and then incorporated into the poly(vinylidene fluoride) (PVDF) matrix. Our results showed that a small amount of TiO ${ }_{2} @$ $\mathrm{SrTiO}_{3} @ P D A N W s$ can simultaneously enhance the breakdown strength and electric displacement of nanocomposite (NC) films, resulting in improved energy storage capability. The 5 wt\% $\mathrm{TiO}_{2}$ @ $_{\mathrm{SrTiO}}$ @ PDA NWs/PVDF NC demonstrates 1.72 times higher maximum discharge energy density compared to pristine PVDF (10.34 J/cm 3 at $198 \mathrm{MV} / \mathrm{m}$ vs. $6.01 \mathrm{~J} / \mathrm{cm}^{3}$ at $\left.170 \mathrm{MV} / \mathrm{m}\right)$. In addition, the NC with $5 \mathrm{wt} \%$ $\mathrm{TiO}_{2} @ \mathrm{SrTiO}_{3} @ P D A N W s$ also demonstrates an excellent charge-discharge efficiency (69\% at 198 $\mathrm{MV} / \mathrm{m}$ ). Enhanced energy storage performance is due to hierarchical interfacial polarization among their multiple interfaces, the large aspect ratio as well as surface modification of the $\mathrm{TiO}_{2} @ \mathrm{SrTiO}_{3}$ NWs. The results of this study provide guidelines and a foundation for the preparation of the polymer NCs with an outstanding discharge energy density.

Dielectric capacitors with the ultrafast charging and discharging speeds, high power density and low cost are very attractive materials for the potential applications in the pulsed power electronic devices, such as radars, lasers, rail guns, and medical defibrillators ${ }^{1-7}$. However, the dielectric capacitors have lower energy density than batteries, fuel cells, and double-layer supercapacitors so this type of energy storage device is still expensive and bulky ${ }^{8-12}$. For instance, the energy density of the biaxial-oriented polypropylenes (BOPP), the best commercially available dielectric material, is $\sim 2 \mathrm{~J} / \mathrm{cm}^{3}$, which is significantly lower than the energy density of a typical electrochemical capacitor (i.e. $\sim 20 \mathrm{~J} / \mathrm{cm}^{3}$ ). Therefore, to miniaturize and reduce the cost of high-power electronic devices, novel materials for dielectric capacitors with dramatically improved energy density are required. PVDF with highly electronegative fluorine atoms exhibits relatively high permittivity and might be a competent candidate to construct high energy density capacitors ${ }^{13-15}$.

The energy density $(\mathrm{U})$ of a dielectric material is typically calculated using the following equation: ${ }^{16}$

$$
\mathrm{U}=\int \mathrm{EdD}
$$

where $\mathrm{E}$ denotes the applied electrical field, and D is electric displacement, which can be calculated using the following equation for linear dielectrics:

$$
\mathrm{D}=\varepsilon_{0} \varepsilon_{\mathrm{r}} \mathrm{E}
$$

where $\varepsilon_{0}$ is the permittivity of vacuum and $\varepsilon_{\mathrm{r}}$ is the relative permittivity of the materials. Thus, the breakdown strength and relative permittivity are important parameters to achieve high energy density. Among several available dielectric materials, ceramic/polymer nanocomposites (NCs) have attracted significant attention as they combine the advantages of ceramic fillers (high permittivity) and the polymer matrix (high breakdown strength, low dielectric loss, flexibility, and low cost $)^{11,17-19}$. However, high content of ceramic particles, usually over $50 \mathrm{vol} \%$, is needed to realize of a high enough permittivity in NCs, resulting in low breakdown strength.

Recent studies have shown that one-dimensional nanofillers with large aspect ratio, such as $\mathrm{TiO}_{2}{ }^{6}, \mathrm{BaTiO}_{3}{ }^{20,21}$, $\mathrm{BaSrTiO}_{3}{ }^{22,23}$, and $\mathrm{SrTiO}_{3}{ }^{24}$, are more effective than the nanoparticles counterparts in improving the permittivity

${ }^{1}$ Lab of Polymer Composites Engineering, Changchun Institute of Applied Chemistry, Chinese Academy of Sciences, Changchun 130022, China. ${ }^{2}$ University of Science and Technology of China, Anhui 230026, China. ${ }^{\square}$ email: ranxh@ciac.ac.cn; wnie@ciac.ac.cn 
and energy density of the dielectric NCs. One-dimensional nanofillers with a large aspect ratio can effectively alleviate the conflict between the raise of permittivity and the decline of breakdown strength. The main reason is that the smaller specific surface of one-dimensional nanofillers helps to reduce the surface energy, which prevents the agglomeration of nanofillers in the polymer matrix. Additionally, one-dimensional nanofillers act as ordered scattering centers for charges and increase the tortuosity of the breakdown path ${ }^{25,26}$.

$\mathrm{TiO}_{2}$ is convenient for large-scale preparation and has a moderate permittivity, which can reduce the permittivity contrast with polymer matrix when it is used as a filler. However, $\mathrm{TiO}_{2}$ possesses a high electrical conductivity, which increases the dielectric loss and reduces the energy efficiency of the $\mathrm{TiO}_{2} /$ polymer NCs, especially at high $\mathrm{TiO}_{2}$ contents ${ }^{3}$. Paraelectric $\mathrm{SrTiO}_{3}$ ceramic material has high permittivity, low electrical conductivity and low remnant polarization, all of which can improve the energy storage capability of the NCs containing $\mathrm{SrTiO}_{3}$ as a filler ${ }^{10,24}$. In addition, the core-shell structured nanofillers can provide large electric displacement via additional polarization in the internal interfaces and might contribute to enhanced energy density of polymer matrix ${ }^{3,25}$. However, polymer nanocomposites, consisting of core-shell structured $\mathrm{TiO}_{2} @ \mathrm{SrTiO}_{3} \mathrm{NWs}$ as nanofillers, have seldom been reported.

In this work, PVDF is chosen as the polymer matrix because its permittivity is higher compared with that of other polymers ${ }^{13-15,27}$. We prepared novel core-shell $\mathrm{TiO}_{2} @ \mathrm{SrTiO}_{3} \mathrm{NWs}$ with the aim to combine the electrical properties of $\mathrm{TiO}_{2}$ and $\mathrm{SrTiO}_{3}$ and to obtain the NCs with high discharge energy density. Our NC design was based on the following assumptions and expectations: (1) Encapsulation of $\mathrm{SrTiO}_{3}$ outer shell inhibits the negative effects of $\mathrm{TiO}_{2} \mathrm{NW}$ s on the NCs properties. (2) Paraelectric ceramic $\mathrm{SrTiO}_{3}$ decreases the remnant polarization of the NCs. (3) $\mathrm{TiO}_{2} @ \mathrm{SrTiO}_{3} \mathrm{NWs}$ would improve permittivity of the NCs better than bare $\mathrm{TiO}_{2} \mathrm{NWs}$, which can be ascribed to additional polarization of the internal interfaces of the nanofillers between crystallized $\mathrm{TiO}_{2}$ and $\mathrm{SrTiO}_{3}$. To better disperse $\mathrm{TiO}_{2} @ \mathrm{SrTiO}_{3} \mathrm{NWs}$ in the PVDF matrix and also to make it more compatible, dopamine was used as a surface modifier. Dielectric properties as well as energy storage capability and efficiency of $\mathrm{TiO}_{2} @ \mathrm{SrTiO}_{3} @ \mathrm{PDA} \mathrm{NW} / \mathrm{PVDF} \mathrm{NCs}$ were systematically studied. NC containing 5 wt\% $\mathrm{TiO}_{2} @ \mathrm{SrTiO}_{3} @ \mathrm{PDA}$ NWs exhibits the highest discharge energy density value (i.e. $10.34 \mathrm{~J} / \mathrm{cm}^{3}$ ) and maintains high charge-discharge efficiency $(69 \%$ at $198 \mathrm{MV} / \mathrm{m})$. Due to the addition of a small amount of the dopamine-modified $\mathrm{TiO}_{2} @ \mathrm{SrTiO}_{3}$ NWs, the corresponding NCs show good mechanical properties. Due to their high energy storage capability, high energy efficiency and excellent mechanical properties, these NCs have the potential for future applications in advanced electric power systems and electronic devices.

\section{Material and experimental methods}

Materials. Kynar 301F PVDF with a density equal to $1.76 \mathrm{~g} / \mathrm{cm}^{3}$ was purchased from Arkema. Molecular weight of PVDF is about 500,000. Strontium hydroxide octahydrate $\left(\mathrm{Sr}(\mathrm{OH})_{2} \cdot 8 \mathrm{H}_{2} \mathrm{O}\right)$, anatase $\mathrm{TiO}_{2}$, Tris(hydroxy-methyl)-aminomethane (Tris, 99\%), dopamine hydrochloride (98\%), N,N-dimethylformamide (DMF) and other reagents were provided by Aladdin (China).

Synthesis of $\mathrm{Na}_{2} \mathrm{Ti}_{3} \mathrm{O} 7$ nanowires. The $\mathrm{Na}_{2} \mathrm{Ti}_{3} \mathrm{O}_{7} \mathrm{NWs}$ were synthesized by a hydrothermal method as described elsewhere ${ }^{28,29} .5 \mathrm{~g}$ of anatase titanium dioxide nanopowder and $100 \mathrm{~mL}$ of $10 \mathrm{M}$ sodium hydroxide aqueous solution were added into a beaker, sonicated for $10 \mathrm{~min}$ and then stirred vigorously at room temperature for $12 \mathrm{~h}$. The mixture was then poured into a $150 \mathrm{~mL}$ teflon-autoclave and kept at $200{ }^{\circ} \mathrm{C}$ for $72 \mathrm{~h}$. The obtained products were collected via centrifugation, dispersed and thoroughly washed with deionized water and ethanol for several times, respectively, followed by vacuum oven-drying at $80^{\circ} \mathrm{C}$ for $12 \mathrm{~h}$.

Synthesis of $\mathrm{TiO}_{2}$ nanowires. The synthesis of $\mathrm{TiO}_{2} \mathrm{NWs}$ was accomplished by using $\mathrm{Na}_{2} \mathrm{Ti}_{3} \mathrm{O}_{7} \mathrm{NWs}$ as raw materials and following the literature procedure ${ }^{30}$. First, the synthesized $\mathrm{Na}_{2} \mathrm{Ti}_{3} \mathrm{O}_{7} \mathrm{NWs}$ were dispersed in $500 \mathrm{~mL}$ of $0.2 \mathrm{M}$ hydrochloric acid aqueous solution and soaked for $24 \mathrm{~h}$. Afterward, the products were collected via centrifugation and dispersed and washed with deionized water and ethanol for several times, respectively, and then dried in a vacuum oven at $80^{\circ} \mathrm{C}$ for $12 \mathrm{~h}$. Finally, to obtain $\mathrm{TiO}_{2} \mathrm{NWs}$, the $\mathrm{H}_{2} \mathrm{Ti}_{3} \mathrm{O}_{7} \mathrm{NWs}$ were heated for $3 \mathrm{~h}$ at $600^{\circ} \mathrm{C}$.

Preparation of $\mathrm{TiO}_{2} @ \mathrm{SrTiO}_{3} \mathbf{N W s}$. The $\mathrm{TiO}_{2} @ \mathrm{SrTiO}_{3} \mathrm{NWs}$ were synthesized by converting $\mathrm{TiO}_{2} \mathrm{NWs}$ surface via hydrothermal method described in literature ${ }^{31}$. The synthesized $\mathrm{TiO}_{2} \mathrm{NWs}$ were placed into a $150 \mathrm{~mL}$ teflon autoclave containing $100 \mathrm{~mL}$ of $\mathrm{Sr}(\mathrm{OH})_{2} \cdot 8 \mathrm{H}_{2} \mathrm{O}$ aqueous solution. The autoclave was heated at $150{ }^{\circ} \mathrm{C}$ for $24 \mathrm{~h}$. The obtained products were collected via centrifugation, dispersed and thoroughly washed with deionized water and ethanol for several times, respectively, followed by vacuum oven-drying at $80^{\circ} \mathrm{C}$ for $12 \mathrm{~h}$. The resulting products are denoted as $\mathrm{TiO}_{2} @ \mathrm{SrTiO}_{3} \mathrm{NWs}$.

Surface modification of nanowires. The $\mathrm{TiO}_{2} @ \mathrm{SrTiO}_{3} \mathrm{NWs}$ were added in $100 \mathrm{~mL}$ of $10 \mathrm{mM}$ Trisbuffer solution (with $\mathrm{pH}=8.5$ ) and sonicated for $10 \mathrm{~min}$. Afterward, $0.5 \mathrm{~g}$ of dopamine hydrochloride was added into the above suspension. The mixture was sonicated for another $10 \mathrm{~min}$ and stirred vigorously at $60^{\circ} \mathrm{C}$ for $12 \mathrm{~h}$. The resulting products were collected via centrifugation, dispersed and thoroughly washed with deionized water and ethanol for several times, respectively, followed by vacuum oven-drying at $80^{\circ} \mathrm{C}$ overnight. The functionalized nanowires are denoted as $\mathrm{TiO}_{2} @ \mathrm{SrTiO}_{3} @ \mathrm{PDA}$ NWs.

Preparation of nanocomposite films. In order to prepare NC films, first, PVDF was added into DMF and stirred vigorously at room temperature for $6 \mathrm{~h}$ to obtain a homogeneous solution. Then the given amount of $\mathrm{TiO}_{2} @ \mathrm{SrTiO}_{3} @ \mathrm{PDA} N W s$ was added in DMF and sonicated for $30 \mathrm{~min}$, after which the PVDF solution was 

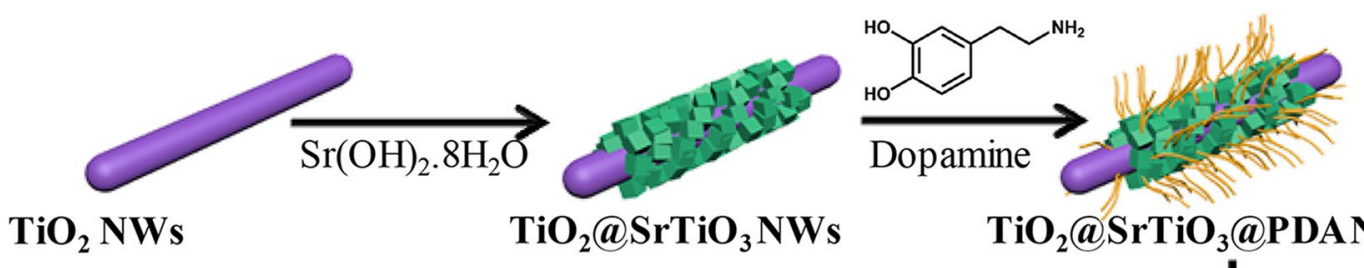

$\mathrm{TiO}_{2} \mathrm{NWs}$

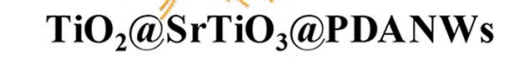

\section{$\mathrm{TiO}_{2} @ \mathrm{SrTiO}_{3} @$ PDANWs/PVDF}

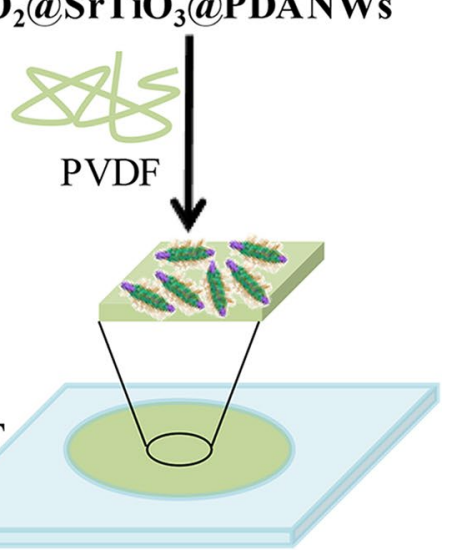

Figure 1. Fabrication scheme for $\mathrm{TiO}_{2} @ \mathrm{SrTiO}_{3} @ \mathrm{PDA} \mathrm{NWs} / \mathrm{PVDF} \mathrm{NCs}$. This figure was created using Autodesk 3D Studio Max 2014 (https://www.autodesk.com) and Microsoft Office PowerPoint 2007 (https:// www.office.com).

added to the above suspension. The mixture was stirred vigorously for $12 \mathrm{~h}$, followed by sonication for $30 \mathrm{~min}$, and then cast onto a smooth and clean glass substrate. The cast films were dried for $12 \mathrm{~h}$ in a vacuum at $60{ }^{\circ} \mathrm{C}$ to evaporate the residual solvent. NCs films with different contents of $\mathrm{TiO}_{2} @ \mathrm{SrTiO}_{3} @ \mathrm{PDA} \mathrm{NWs}(1 \mathrm{wt} \%, 5 \mathrm{wt} \%$ and $15 \mathrm{wt} \%$ ) were fabricated. For comparison, the $15 \mathrm{wt} \% \mathrm{SrTiO}_{3} @ \mathrm{PDA}$ NWs/PVDF NC and 15 wt $\% \mathrm{TiO}_{2} @$ PDA NWs/PVDF NC were also prepared using the same procedure. The NC films were about $50 \mu \mathrm{m}$ thick. The procedure for fabrication of $\mathrm{TiO}_{2} @ \mathrm{SrTiO}_{3} @ \mathrm{PDA} \mathrm{NWs} / \mathrm{PVDF} \mathrm{NCs}$ is demonstrated in Fig. 1.

Characterization. Bruker Vertex 70 spectrometer was used to record the Fourier-transform infrared (FTIR) spectra. XL30 scanning electron microscope (SEM) manufactured by FEI Co. (Netherlands) was used to analyze the morphology of the synthesized NWs and the NC film. The JEOL-1011 Transmission electron microscope (TEM) manufactured by JEOL Co. (Japan) was employed to analyze the morphology of the synthesized NWs. X-ray diffraction (XRD) was performed by the D8 Advanced diffractometer (Bruker, Germany) using $\mathrm{CuKa}$ radiation as an $\mathrm{X}$-ray source with a $3 \% \mathrm{~min}$ scanning rate. X-ray photoelectron spectroscopy (XPS) was performed using Thermo Scientific ESCALAB 250 to analyze the surface composition of the synthesized NWs. Thermogravimetric analysis (TGA) was done using Q500 analyzer (TA Co., USA) in the $\mathrm{N}_{2}$ atmosphere at a $10{ }^{\circ} \mathrm{C} / \mathrm{min}$ heating rate. The crystallization behavior of the PVDF matrix was analyzed by differential scanning calorimetry (DSC) using the Q20 instrument (TA Co., USA) conducted in the $\mathrm{N}_{2}$ atmosphere in the $50-200^{\circ} \mathrm{C}$ range at $10^{\circ} \mathrm{C} / \mathrm{min}$ heating and cooling rates.

The permittivity and loss of the NCs were obtained using Novocontrol Concept 40 broadband dielectric spectrometer. Measurements were performed at room temperature in the $100 \mathrm{~Hz}-1 \mathrm{MHz}$ frequency range. Both sides of the samples were coated with silver paste to characterize the dielectric properties. The electric displacement-electric field (D-E) hysteresis measurements were conducted by the Precision Multiferroic Materials Analyzer manufactured by Radiant Co. (USA). Both sides of the samples were coated with gold, which acts as the electrodes for D-E hysteresis measurement. The diameter and thickness of the gold electrodes are $2 \mathrm{~mm}$ and $50-100 \mathrm{~nm}$, respectively. The mechanical tensile properties were tested using a universal Instron 5869 machine (Instron Engineer Co., USA) at $1 \mathrm{~mm} / \mathrm{min}$ strain rate.

\section{Results and discussion}

Characterization of the nanowires. The core-shell structured $\mathrm{TiO}_{2} @ \mathrm{SrTiO}_{3} \mathrm{NWs}$ were synthesized by $\mathrm{TiO}_{2}$ surface conversion. TEM and SEM images demonstrated that the $\mathrm{SrTiO}_{3}$ nanocubes were successfully encapsulated on the surface of $\mathrm{TiO}_{2} \mathrm{NWs}$, as shown in Fig. S1 and 2. Figure 2a,c show that the surface of pure $\mathrm{TiO}_{2}$ NWs is smooth. However, Fig. $2 \mathrm{~b}$ as well as $2 \mathrm{~d}$ shows that the smooth surface is uniformly covered by regularly-shaped $\mathrm{SrTiO}_{3}$ nanocubes after hydrothermal treatment in $\mathrm{Sr}(\mathrm{OH})_{2} \cdot 8 \mathrm{H}_{2} \mathrm{O}$ solution. Based on SEM results, the average length and average diameter of $\mathrm{TiO}_{2} / \mathrm{SrTiO}_{3} \mathrm{NWs}$ are calculated to be $6.3 \mu \mathrm{m}$ and $320 \mathrm{~nm}$, respectively (Fig. S2). As a consequence, the calculated aspect ratio of $\mathrm{TiO}_{2} / \mathrm{SrTiO}_{3} \mathrm{NWs}$ approximates to 20 . The large aspect ratio could decrease the percolation threshold of the NCs, achieving high energy density at a lower additive amount. The crystal phases of $\mathrm{TiO}_{2} \mathrm{NWs}$ as well as $\mathrm{TiO}_{2} @ \mathrm{SrTiO}_{3} \mathrm{NWs}$ were analysed by the XRD patterns (Fig. 3a). The diffraction peaks of $\mathrm{TiO}_{2} \mathrm{NWs}$ are consistent with the anatase $\mathrm{TiO}_{2}$ crystal structure according to the JCPDS card number 21-1272 $2^{31}$. After hydrothermal treatment of $\mathrm{TiO}_{2} \mathrm{NWs}$, the products exhibit 



Figure 2. SEM images of (a) pristine $\mathrm{TiO}_{2} \mathrm{NWs}$ and (b) $\mathrm{TiO}_{2} @ \mathrm{SrTiO}_{3} \mathrm{NWs}$ TEM images of (c) pristine $\mathrm{TiO}_{2}$ NWs and (d) $\mathrm{TiO}_{2} @ \mathrm{SrTiO}_{3}$ NWs. This figure was created using Autodesk 3D Studio Max 2014 (https://www. autodesk.com) and Microsoft Office PowerPoint 2007 (https://www.office.com).

(a)
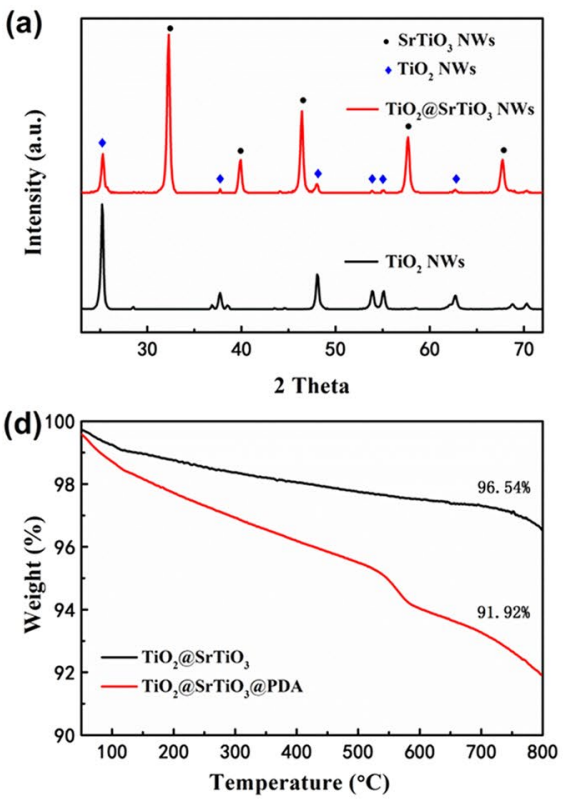

(b)
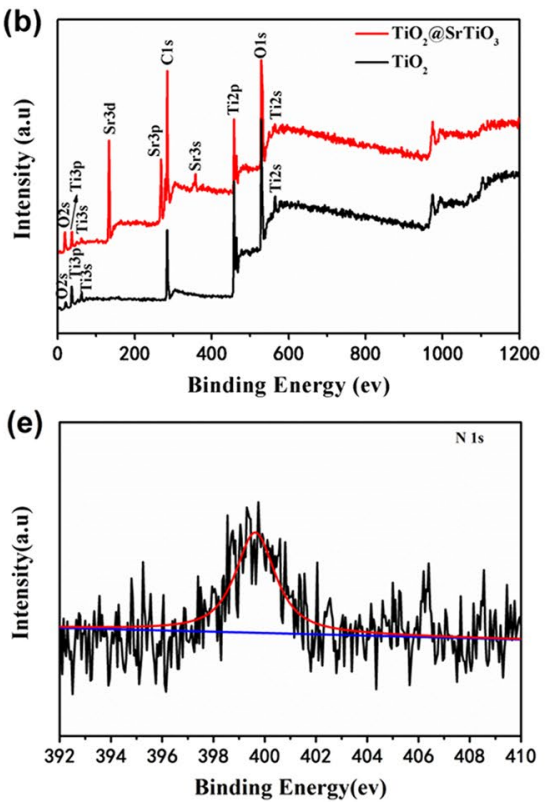



(f)

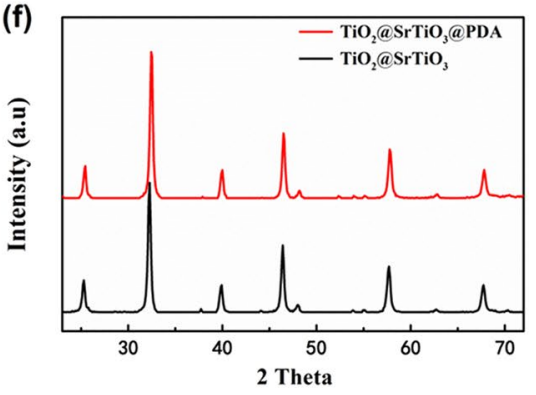

Figure 3. (a) XRD patterns and (b) XPS spectra of $\mathrm{TiO}_{2} \mathrm{NWs}$ and $\mathrm{TiO}_{2} @ \mathrm{SrTiO}_{3} \mathrm{NWs}$. (c) FT-IR spectra (d) TGA curves of $\mathrm{TiO}_{2} @ \mathrm{SrTiO}_{3} \mathrm{NWs}$ and $\mathrm{TiO}_{2} @ \mathrm{SrTiO}_{3} @ \mathrm{PDA} \mathrm{NWs}$. (e) High-resolution XPS spectrum of $\mathrm{N}_{1 \mathrm{~s}}$ of $\mathrm{TiO}_{2} @ S r T i O_{3} @ P D A$ NWs. (f) XRD patterns of $\mathrm{TiO}_{2} @ \mathrm{SrTiO}_{3} \mathrm{NWs}$ and $\mathrm{TiO}_{2} @ \mathrm{SrTiO}_{3} @ \mathrm{PDA}$ NWs. This figure was created using OriginLab OriginPro 8.5 (https://www.originlab.com) and Microsoft Office PowerPoint 2007 (https://www.office.com).

some additional peaks, which could be ascribed to the characteristic peaks of cubic $\mathrm{SrTiO}_{3}$ according to JCPDS card number $35-734^{31}$, indicating a successful $\mathrm{TiO}_{2}$ surface conversion. Besides, XPS spectra also indicated the generation of $\mathrm{SrTiO}_{3}$ on the surface of $\mathrm{TiO}_{2}$. XPS spectrum of $\mathrm{TiO}_{2} @ \mathrm{SrTiO}_{3}$ showed peaks corresponding to $\mathrm{Sr} 3 \mathrm{~d}$ and $\mathrm{Sr} 3 \mathrm{p}$, which were not present in the XPS spectrum of pristine $\mathrm{TiO}_{2}$ NWs (Fig. 3b).

To better disperse $\mathrm{TiO}_{2} @ \mathrm{SrTiO}_{3} \mathrm{NWs}$ and make them more compatible with the PVDF matrix, dopamine was used as a surface modifier. The catechol and amino functional groups of dopamine can form covalent and 


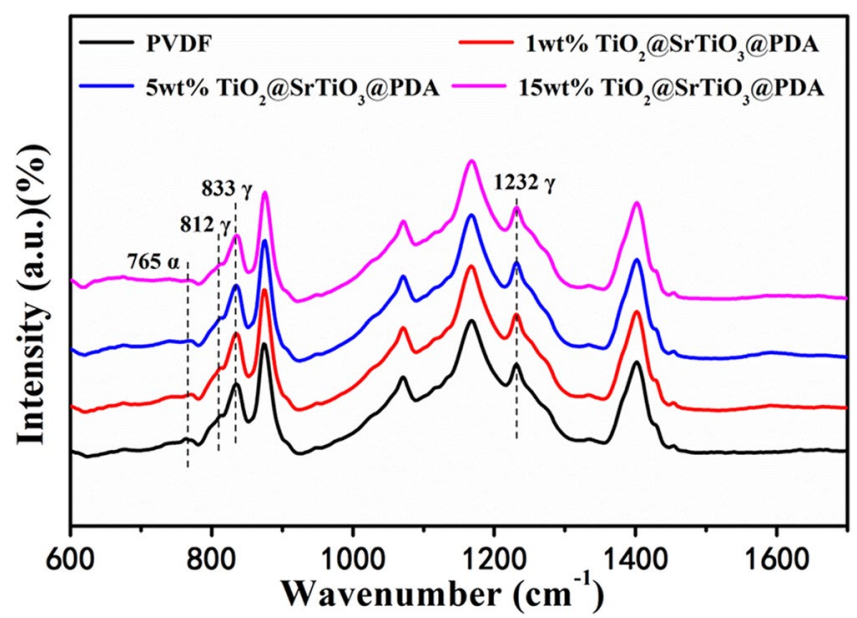

Figure 4. The FTIR spectra of PVDF and $\mathrm{TiO}_{2} @ \mathrm{SrTiO}_{3} @ \mathrm{PDA} \mathrm{NWs} / \mathrm{PVDF} \mathrm{NCs}$ containing different contents of $\mathrm{TiO}_{2} @ \mathrm{SrTiO}_{3} @ \mathrm{PDA}$ NWs. This figure was created using OriginLab OriginPro 8.5 (https://www.originlab. com).

non-covalent interactions with the surface of the $\mathrm{TiO}_{2} @ \mathrm{SrTiO}_{3} \mathrm{NW}$, which lead to the dopamine adhere to the surface of the $\mathrm{TiO}_{2} @ \mathrm{SrTiO}_{3} \mathrm{NW}^{32-34}$. And oxidative self-polymerization of dopamine resulted in the formation of dense and robust layers on the $\mathrm{TiO}_{2} @ \mathrm{SrTiO}_{3} \mathrm{NW}$ surface (Fig. S3) ) $^{15,21,27,35}$. The FT-IR and TGA analysis confirmed the successful coating of polydopamine on the surface of $\mathrm{TiO}_{2} @ \mathrm{SrTiO}_{3} \mathrm{NWs}$. As shown in Fig. 3c, the FT-IR spectrum of $\mathrm{TiO}_{2} @ \mathrm{SrTiO}_{3} @ \mathrm{PDA}$ NWs shows a band that is absent in the FT-IR spectrum of $\mathrm{TiO}_{2} @ \mathrm{SrTiO}_{3}$ NWs. The infrared absorption peak at $1268 \mathrm{~cm}^{-1}$ is attributed to the $-\mathrm{C}-\mathrm{N}$ stretching vibration ${ }^{27,36}$. The signal belongs to dopamine and is not observed in the $\mathrm{TiO}_{2} @ \mathrm{SrTiO}_{3} \mathrm{NWs}$. In addition, the peak at 3100-3700 $\mathrm{cm}^{-1}$, which is attributed to $-\mathrm{NH}$ and/or -OH stretching vibrations, becomes stronger in the $\mathrm{TiO}_{2} @ \mathrm{SrTiO}_{3} @ \mathrm{PDA}$ NWs compared with that in the $\mathrm{TiO}_{2} @ \mathrm{SrTiO}_{3} \mathrm{NWs}$. These results indicate successful surface modification by dopamine. Due to the degradation of polydopamine which adheres to the $\mathrm{TiO}_{2} @ \mathrm{SrTiO}_{3} \mathrm{NWs}_{\text {surface, the }}$ $\mathrm{TiO}_{2} @ \mathrm{SrTiO}_{3} @ \mathrm{PDA} \mathrm{NWs}$ have a higher weight loss compared to the unmodified $\mathrm{TiO}_{2} @ S r T i \mathrm{O}_{3} \mathrm{NWs}$ (Fig. 3d). The surface elemental composition of the $\mathrm{TiO}_{2} @ \mathrm{SrTiO}_{3} @ \mathrm{PDA} \mathrm{NWs}$ was further investigated by XPS analysis. Figure 3e shows the appearance of $\mathrm{N}_{1 \mathrm{~s}}$ peak in the high-resolution XPS spectrum of $\mathrm{TiO}_{2} @ \mathrm{SrTiO}_{3} @ \mathrm{PDA} \mathrm{NWs}$, which confirms the presence of polydopamine on the $\mathrm{TiO}_{2} @ \mathrm{SrTiO}_{3}$ surface ${ }^{21}$. The XRD analysis was used to investigate the crystal phases of the $\mathrm{TiO}_{2} @ \mathrm{SrTiO}_{3} \mathrm{NWs}$ and $\mathrm{TiO}_{2} @ \mathrm{SrTiO}_{3} @ \mathrm{PDA} \mathrm{NWs}$. As shown in Fig. 3f, the XRD pattern of $\mathrm{TiO}_{2} @ \mathrm{SrTiO}_{3} \mathrm{NWs}$ did not change after surface modification, indicating that the surface modification has no effect on the crystalline structure.

Characterization of the TiO @SrTiO $_{3} @ P D A$ NWs/PVDF nanocomposites. The FTIR spectra of $\mathrm{TiO}_{2} @ \mathrm{SrTiO}_{3} @ P D A N W s / \mathrm{PVDF}$ NCs containing different contents of $\mathrm{TiO}_{2} @ \mathrm{SrTiO}_{3} @ P D A$ NWs are shown in Fig. 4. The FTIR spectra demonstrated that the crystalline phase of PVDF is mainly $\gamma$-phase. As seen from Fig. 4, all samples show strong infrared absorption peaks at 812,833 , and $1232 \mathrm{~cm}^{-1}$, indicating that $\gamma$-phase was formed in the samples. The peak at $765 \mathrm{~cm}^{-1}$ is ascribed to $\alpha$-phase and remains unchanged after introduction of $\mathrm{TiO}_{2} @ \mathrm{SrTiO}_{3} @ \mathrm{PDA} \mathrm{NWs}$, indicating negligible phase transition from $\alpha$-phase to $\gamma$-phase ${ }^{37}$. The polar $\gamma$-phase usually presents high breakdown strength, which is favorable for enhancing the energy density of the $\mathrm{NCs}^{38}$.

The SEM images and mapping images of the 5 wt\% TiO $\mathrm{T}_{2} @ \mathrm{SrTiO}_{3} @ \mathrm{PDA}$ NWs/PVDF NC are shown in Fig. 5. The SEM images show the nanofillers are dispersed homogeneously in the PVDF matrix with little agglomeration, and they orient in the in-plane direction relative to the PVDF matrix (Fig. 5a,b). This is beneficial for improving the breakdown strength and energy density of the NCs. Moreover, the film has a very small amount of defects (such as visible voids or flaws), which originates from the good interfacial compatibility between the PVDF matrix and nanofillers induced by hydrogen bonds between the PVDF and polydopamine. The cross-section SEM mapping images of the $5 \mathrm{wt} \% \mathrm{TiO}_{2} @ \mathrm{SrTiO}_{3} @ \mathrm{PDA}$ NWs/PVDF NC further confirm that the distribution of nanofillers in PVDF matrix is homogeneous (Fig. 5c). The energy dispersive X-ray spectrum (EDS) corresponding to the cross-section SEM mapping images of 5 wt\% $\mathrm{TiO}_{2} @ \mathrm{SrTiO}_{3} @ \mathrm{PDA}$ NWs/PVDF NC shows C, N, O, F, $\mathrm{Ti}$ and Sr peaks, as shown in Fig. 5d. Inset of Fig. 5d shows each elemental composition percentage.

Thermal and crystallization behavior of the $\mathrm{TiO}_{2} @ \mathrm{SrTiO}_{3} @ P D A$ NWs/PVDF nanocomposites. DSC curves were used to analyze the influence of the weight fractions of $\mathrm{TiO}_{2} @ \mathrm{SrTiO}_{3} @ \mathrm{PDA} \mathrm{NWs}$ on the crystallization behavior of the PVDF matrix. As shown in Fig. 6 and Table 1, the melting temperature and crystallization temperature of the NCs are slightly changed compared to the pure PVDF. The crystallinity $\left(\mathrm{X}_{c}\right)$ of PVDF is calculated using the following Eq. ${ }^{39}$ :

$$
\mathrm{Xc}(\%)=\frac{\Delta \mathrm{H}_{\mathrm{m}}}{(1-\mathrm{w}) \Delta \mathrm{H}_{\mathrm{m}}^{0}} \times 100 \%
$$






Figure 5. (a) The top-view and (b) cross-section SEM images of 5 wt $\% \mathrm{TiO}_{2} @ S r T i \mathrm{O}_{3} @ P D A N W s / \mathrm{PVDF}$ NC. (c) The cross-section SEM mapping images of 5 wt\% TiO $\mathrm{T}_{2} @ S r T i \mathrm{O}_{3} @ P D A N W s / P V D F ~ N C$. (d) EDS corresponding to the cross-section SEM mapping images. This figure was created using OriginLab OriginPro 8.5 (https://www.originlab.com) and Microsoft Office PowerPoint 2007 (https://www.office.com).
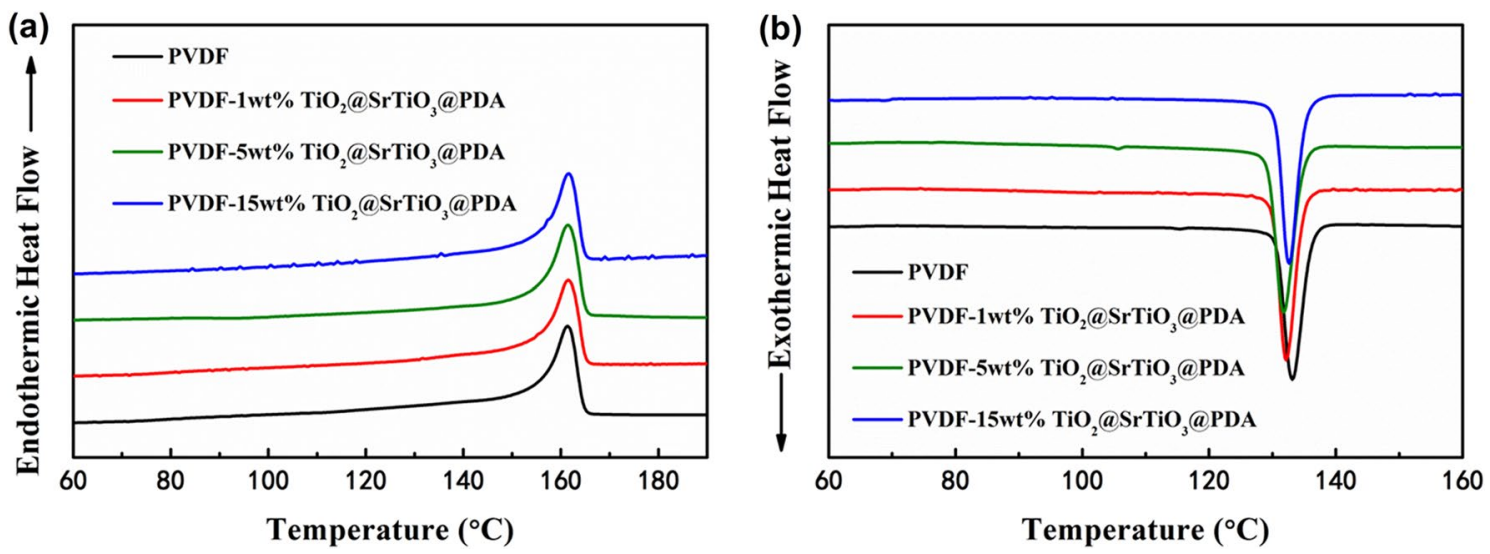

Figure 6. (a) Heating curves as well as (b) cooling curves of the pure PVDF and $\mathrm{TiO}_{2} @ \mathrm{SrTiO}_{3} @ \mathrm{PDA} \mathrm{NWs} /$ PVDF NCs. This figure was created using OriginLab OriginPro 8.5 (https://www.originlab.com) and Microsoft Office PowerPoint 2007 (https://www.office.com).

\begin{tabular}{|l|l|l|l|}
\hline Samples & $\mathbf{T}_{\mathbf{c}}\left({ }^{\circ} \mathbf{C}\right)$ & $\mathbf{T}_{\mathbf{m}}\left({ }^{\circ} \mathbf{C}\right)$ & $\mathbf{X}_{\mathbf{c}}(\%)$ \\
\hline PVDF & 133.1 & 161.5 & 40.1 \\
\hline $1 \mathrm{wt} \% \mathrm{TiO}_{2} @ \mathrm{SrTiO}_{3} @ \mathrm{PDA}$ & 132.1 & 161.5 & 46.5 \\
\hline $5 \mathrm{wt} \% \mathrm{TiO}_{2} @ \mathrm{SrTiO}_{3} @ \mathrm{PDA}$ & 131.8 & 161.5 & 45.7 \\
\hline $15 \mathrm{wt} \% \mathrm{TiO}_{2} @ \mathrm{SrTiO}_{3} @ \mathrm{PDA}$ & 132.6 & 161.5 & 43.1 \\
\hline
\end{tabular}

Table 1. Crystallization temperature $\left(\mathrm{T}_{\mathrm{c}}\right)$, melting temperature $\left(\mathrm{T}_{\mathrm{m}}\right)$ and crystallinity $\left(\mathrm{X}_{\mathrm{c}}\right)$ derived from the DSC measurements of pure PVDF and $\mathrm{TiO}_{2} @ \mathrm{SrTiO}_{3} @ \mathrm{PDA}$ NWs/PVDF NCs in Fig. 6. 



Figure 7. Frequency dependence of (a) permittivity and (b) dielectric loss of pristine PVDF and the $\mathrm{TiO}_{2} @$ $\mathrm{SrTiO}_{3} @ P D A$ NWs/PVDF NCs. Frequency dependence of (c) permittivity and (d) dielectric loss of $\mathrm{TiO}_{2} @$ $\mathrm{SrTiO}_{3} @ \mathrm{PDA} N \mathrm{~N}$ s/PVDF, $\mathrm{SrTiO}_{3} @ P D A N W$ N/PVDF and $\mathrm{TiO}_{2} @ \mathrm{PDA}$ NWs/PVDF with 15 wt\% of fillers. This figure was created using OriginLab OriginPro 8.5 (https://www.originlab.com) and Microsoft Office PowerPoint 2007 (https://www.office.com).

where $\Delta \mathrm{H}_{\mathrm{m}}$ and $\Delta \mathrm{H}_{\mathrm{m}}{ }^{0}$ (equal to $104.7 \mathrm{~J} / \mathrm{g}^{40}$ ) are melting enthalpies of the sample and a completely crystalline PVDF, respectively, and $w$ is the weight percentage of the $\mathrm{TiO}_{2} @ \mathrm{SrTiO}_{3} @ \mathrm{PDA}$ NWs in the NCs. The crystallinities of polymer in the NCs are calculated and summarized, as shown in Table 1 . The crystallinity is enhanced from $40.1 \%$ for the pure PVDF to $46.5 \%$ for the 1 wt $\% \mathrm{TiO}_{2} @ \mathrm{SrTiO}_{3} @ \mathrm{PDA}$ NWs/PVDF NC. However, the crystallinity declines with further increasing the weight fractions of $\mathrm{TiO}_{2} @ S r T i \mathrm{~S}_{3} @ \mathrm{PDA} \mathrm{NWs}$ since nanofillers have a two-side influence on the crystallization behavior of the polymer matrix ${ }^{39}$. On one hand, the addition of $\mathrm{TiO}_{2} @ \mathrm{SrTiO}_{3} @ \mathrm{PDA} N W s$ provides more heterogeneous nucleation sites, thus reducing the nucleation energy and promoting the crystallization of the PVDF matrix. On the other hand, TiO ${ }_{2} @ S r T i O_{3} @ \mathrm{PDA}_{\mathrm{NW}}$ act as physical obstacles, hindering the PVDF polymer chain motions. All the NCs display a relatively higher crystallinity compared to the pure PVDF, which is attributed to the nucleation effect of $\mathrm{TiO}_{2} @ \mathrm{SrTiO}_{3} @ \mathrm{PDA} \mathrm{NWs}$ as the main factor affecting the crystallization of PVDF matrix.

Dielectric properties of the TiO @SrTiO $_{3}$ @PDA NWs/PVDF nanocomposites. The broadband dielectric spectrometer was used to measure the frequency-dependences of the permittivity and dielectric loss of PVDF and NC films with different weight fractions of $\mathrm{TiO}_{2} @ \mathrm{SrTiO}_{3} @ \mathrm{PDA}$ NWs. As shown in Fig. 7a, the permittivity of the NCs increases monotonously with increasing the content of nanowires, which can be interpreted as follows: (1) The permittivity of the large aspect ratio nanowires is higher than that of PVDF matrix. (2) The incorporation of $\mathrm{TiO}_{2} @ \mathrm{SrTiO}_{3} @ \mathrm{PDA}$ NWs into the PVDF matrix leads to hierarchical interfacial polarization in the $\mathrm{TiO}_{2} / \mathrm{SrTiO}_{3}$ interface and $\mathrm{SrTiO}_{3} / \mathrm{PVDF}$ interface, as shown in Fig. 8. In addition, with increasing the content of $\mathrm{TiO}_{2} @ \mathrm{SrTiO}_{3} @ \mathrm{PDA} \mathrm{NWs}$, the interfacial polarization increases, as a result, the permittivity in the NCs increases. For 15 wt\% of $\mathrm{TiO}_{2} @ \mathrm{SrTiO}_{3} @ \mathrm{PDA}$ NWs/PVDF NC, the permittivity reaches up to 10.2 (at $100 \mathrm{~Hz}$ ), which is larger than the value for pristine PVDF (i.e. 8.3 at $100 \mathrm{~Hz}$ ). Meanwhile, the permittivity of the pure PVDF and NCs decreases with increasing the frequency since the dipoles of nanofillers and polymer cannot keep up with the change of external frequency as the applied electric field frequency increases ${ }^{41}$. As shown in Fig. 7b, due to decreasing the interface relaxation polarization loss, the dielectric loss of the NC films decreases as frequency increases in the $10^{2}-10^{4} \mathrm{~Hz}$ range. However, in the $10^{4}-10^{6} \mathrm{~Hz}$ range, the dielectric loss increases sharply as frequency increases due to the $\alpha_{a}$ relaxation related to the PVDF glass transition ${ }^{42,43}$.

To understand the effect of $\mathrm{SrTiO}_{3}$ shell on the dielectric properties of the NCs, the dielectric performances of the NCs with 15 wt\% TiO $@ \mathrm{SrTiO}_{3} @ P D A N W s, \mathrm{NrTiO}_{3} @ P D A N W s$ and TiO $@$ @PDA NWs were studied. As shown in Fig. 7c, at the same frequency, the 15 wt $\% \mathrm{TiO}_{2} @ \mathrm{SrTiO}_{3} @ \mathrm{PDA} / \mathrm{PVDF} \mathrm{NC}$ shows higher permittivity 




Figure 8. Dipole as well as interfacial polarization schematic for the $\mathrm{TiO}_{2} @ S r T i \mathrm{O}_{3} @ \mathrm{PDA} \mathrm{NWs} / \mathrm{PVDF} \mathrm{NCs}$ under an external electric field. This figure was created using Microsoft Office PowerPoint 2007 (https://www. office.com).

compared to the $15 \mathrm{wt} \% \mathrm{SrTiO}_{3} @ \mathrm{PDA} / \mathrm{PVDF} \mathrm{NC}$ and $15 \mathrm{wt} \% \mathrm{TiO}_{2} @ \mathrm{PDA}$ NWs/PVDF NC, which is ascribed to the additional interfacial polarization induced in the interfacial region of core-shell structured nanofillers. Due to the difference of the Fermi levels, permittivity as well as electrical conductivity between $\mathrm{TiO}_{2}$ and $\mathrm{SrTiO}_{3}{ }^{44}$, charge accumulates at the $\mathrm{TiO}_{2} / \mathrm{SrTiO}_{3}$ interface in the nanofillers when an electric field is applied (Fig. 8), causing Maxwell-Wagner-Sillars (MWS) interfacial polarization and the enhancement of the permittivity. Moreover, the 15 wt\% $\mathrm{TiO}_{2} @ \mathrm{SrTiO}_{3} @ \mathrm{PDA} / \mathrm{PVDF} \mathrm{NC}$ has a lower dielectric loss than the $15 \mathrm{wt} \% \mathrm{SrTiO}_{3} @ \mathrm{PDA} / \mathrm{PVDF}$ NC and 15 wt\% TiO $\mathrm{TiPDA}_{2}$ NWs/PVDF NC at $100 \mathrm{~Hz}$ (Fig. 7d), which can be attributed to the influence of $\mathrm{TiO}_{2} @$ $\mathrm{SrTiO}_{3} \mathrm{NWs}$ core-shell structure.

Breakdown strength of the $\mathrm{TiO}_{2}$ @SrTiO $_{3} @ P D A$ NWs/PVDF nanocomposites. The breakdown strength plays an important role in determining the energy storage performance of dielectric materials. The breakdown strength of the PVDF and corresponding NCs is analyzed by Weibull statistics as follows ${ }^{21,45,46}$ :

$$
\mathrm{P}(\mathrm{E})=1-\exp \left[-\left(\frac{\mathrm{E}}{\mathrm{E}_{\mathrm{b}}}\right)^{\beta}\right]
$$

where $\mathrm{P}(\mathrm{E})$ is the cumulative probability of electric failure, $\beta$ quantifies the data scattering degree, $\mathrm{E}$ and $\mathrm{E}_{\mathrm{b}}$ are experimental breakdown strength and characteristic breakdown strength (which is breakdown strength at the cumulative failure probability of 63.2\%), respectively. Figure 9 shows breakdown strength Weibull plots of NCs containing different contents of $\mathrm{TiO}_{2} @ \mathrm{SrTiO}_{3} @ \mathrm{PDA} \mathrm{NWs}$, indicating that the introduction of $\mathrm{TiO}_{2} @ \mathrm{SrTiO}_{3} @$ PDA NWs in PVDF matrix can improve the breakdown strength of NCs. It can be observed that the highest breakdown strength of $198 \mathrm{MV} / \mathrm{m}$ can be achieved for the NC film containing 5 wt\% TiO ${ }_{2} @ S_{1} \mathrm{TiO}_{3} @ \mathrm{PDA} \mathrm{NWs}$, which is higher than the corresponding value for pure PVDF $(170 \mathrm{MV} / \mathrm{m})$. The enhanced breakdown strength of NCs can be interpreted as follows: (1) The large aspect ratio nanofillers orient in the in-plane directions of the PVDF matrix during solution casting, which might reduce the concentration of the electric field, act as ordered charge scattering centers and increase the tortuosity of the breakdown path ${ }^{25,26}$; (2) The $\mathrm{SrTiO}_{3}$ outer shell inhibits the adverse effects of $\mathrm{TiO}_{2} \mathrm{NWs}$ on NCs, such as high electric conductivity, thus decreasing the leakage current density and dielectric loss; (3) Dopamine modification improves the dispersibility of the $\mathrm{TiO}_{2} @ \mathrm{SrTiO}_{3} \mathrm{NWs}$ as well as their compatibility with the PVDF matrix ${ }^{15,21}$. Besides, the breakdown strength of the NCs decreases as the weight fraction of nanofillers further increases, because the introduction of more nanofillers into the PVDF matrix inevitably results in more defects. To study the effect of $\mathrm{SrTiO}_{3}$ shell on the breakdown strength of the NCs, breakdown strength Weibull plot of the 15 wt\% SrTiO $@$ PDA NWs/PVDF and TiO $@$ @PDA NWs/PVDF are also shown in Fig. 9. The NC containing 15 wt\% $\mathrm{TiO}_{2} @ \mathrm{SrTiO}_{3} @ \mathrm{PDA}$ NWs exhibits a higher breakdown strength than the NCs containing 15 wt\% SrTiO $@ P D A N W s$ and $\mathrm{TiO}_{2} @ P D A N W s$, which is ascribed to the inhibition effect of $\mathrm{SrTiO}_{3}$ shell on $\mathrm{TiO}_{2}$ core. Most of the charges in the $\mathrm{NCs}$ containing $\mathrm{TiO}_{2} @ \mathrm{SrTiO}_{3} \mathrm{NWs}_{\text {can }}$ only transfer in the interfacial region of core-shell structured nanofillers, leading to reduced electric percolation pathway and enhanced breakdown strength ${ }^{3}$.

Energy storage performance of the $\mathrm{TiO}_{2}$ @SrTiO $_{3} @ P D A \mathrm{NWs} / \mathrm{PVDF}$ nanocomposites. To determine the energy storage performance, D-E loops of pure PVDF and the NCs are measured at $100 \mathrm{~Hz}$ as shown in Fig. 10 and S4. The introduction of the surface-modified $\mathrm{TiO}_{2} @ \mathrm{SrTiO}_{3} \mathrm{NWs}$ improves maximum electric displacement (Fig. S5a), due to the higher permittivity of $\mathrm{TiO}_{2} @ \mathrm{SrTiO}_{3} @ P D A$ NWs and hierarchical interfacial polarization among $\mathrm{TiO}_{2}, \mathrm{SrTiO}_{3}$ and PVDF interfaces. The charged energy density and discharge energy density of the NCs are shown in Figs. S6 and 11a. Under the same electric field, the charged energy den- 


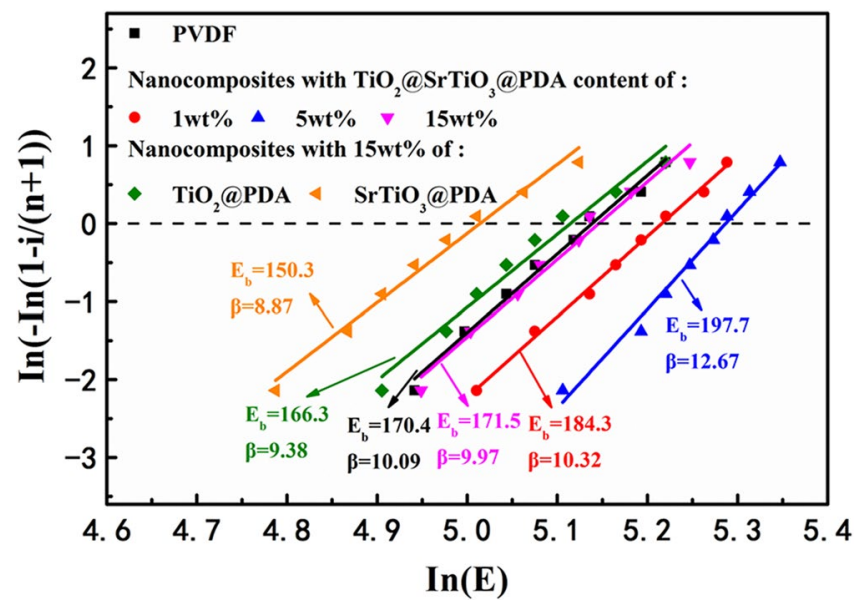

Figure 9. Breakdown strength Weibull plots of PVDF, NCs containing different contents of $\mathrm{TiO}_{2} @ \mathrm{SrTiO}_{3} @$ PDA NWs, 15 wt\% $\mathrm{SrTiO}_{3} @ P D A$ NWs and 15 wt\% TiO $2 @ P D A$ NWs. This figure was created using OriginLab OriginPro 8.5 (https://www.originlab.com).



Figure 10. D-E loops of NCs filled with different weight fractions of $\mathrm{TiO}_{2} @ \mathrm{SrTiO}_{3} @ \mathrm{PDA} \mathrm{NWs}$ at $100 \mathrm{~Hz}$ and room temperature before the NCs broke down. This figure was created using OriginLab OriginPro 8.5 (https:// www.originlab.com).

sity of NCs increases with increasing the weight fractions of the nanofillers (Fig. S6). This can be ascribed to the high electric displacement of the NCs induced by the presence of the $\mathrm{TiO}_{2} @ \mathrm{SrTiO}_{3} @ \mathrm{PDA} \mathrm{NWs}$ possessing high permittivity. It can be observed that the $5 \mathrm{wt} \% \mathrm{TiO}_{2} @ \mathrm{SrTiO}_{3} @ \mathrm{PDA} \mathrm{NWs} / \mathrm{PVDF} \mathrm{NC}$ exhibits maximum charged energy density of $14.95 \mathrm{~J} / \mathrm{cm}^{3}$ at $198 \mathrm{MV} / \mathrm{m}$, which is larger compared to that of pure PVDF (i.e. $8.34 \mathrm{~J} / \mathrm{cm}^{3}$ at $170 \mathrm{MV} / \mathrm{m}$ ) (Fig. S6). The maximum discharge energy density of $10.34 \mathrm{~J} / \mathrm{cm}^{3}$ can be achieved in $5 \mathrm{wt} \% \mathrm{TiO}_{2} @$ $\mathrm{SrTiO}_{3} @ \mathrm{PDA} \mathrm{NWs} / \mathrm{PVDF} \mathrm{NC}$ at $198 \mathrm{MV} / \mathrm{m}$, which is indeed 1.72 times larger than the corresponding value for pure PVDF $\left(6.01 \mathrm{~J} / \mathrm{cm}^{3}\right.$ at $170 \mathrm{MV} / \mathrm{m}$ ) (Fig. 11a). The largest discharge energy density of NC film originates from the simultaneous enhancement of the effective electric displacement $\left(D_{\max }-\mathrm{D}_{\mathrm{r}}\right)$ and breakdown strength by the introduction of a small amount of dopamine-modified $\mathrm{TiO}_{2} @ \mathrm{SrTiO}_{3} \mathrm{NWs}$ (Fig. S5b and 9). Table 2 summarizes the energy storage performance of $\mathrm{TiO}_{2} @ \mathrm{SrTiO}_{3} @ \mathrm{PDA} \mathrm{NW} / \mathrm{PVDF} \mathrm{NC}$ and some previously reported dielectric NCs. It can be observed that the NCs in this study exhibit comparable or higher discharge energy density than that of previously reported dielectric NC films ${ }^{16,47-57}$. High discharge energy density is due to the additional interfacial polarization induced in the interfacial region of $\mathrm{TiO}_{2} @ \mathrm{SrTiO}_{3} \mathrm{NWs}$ and high permittivity and low remnant polarization of paraelectric ceramic $\mathrm{SrTiO}_{3}$ shell.

Both high discharge energy density and energy efficiency $(\eta)$ of energy storage capacitors are desired for practical applications. The discharge energy efficiency $(\eta)$ can be calculated by the following equation:

$$
\eta=\mathrm{U}_{\text {dis }} / \mathrm{U}_{\text {stor }}
$$

where $U_{\text {dis }}$ and $U_{\text {stor }}$ are the discharge and charge energy densities of the NCs, respectively. The discharge energy efficiencies of pure PVDF and the NCs are shown in Fig. 11b. The efficiency of the NC with 5 wt\% 

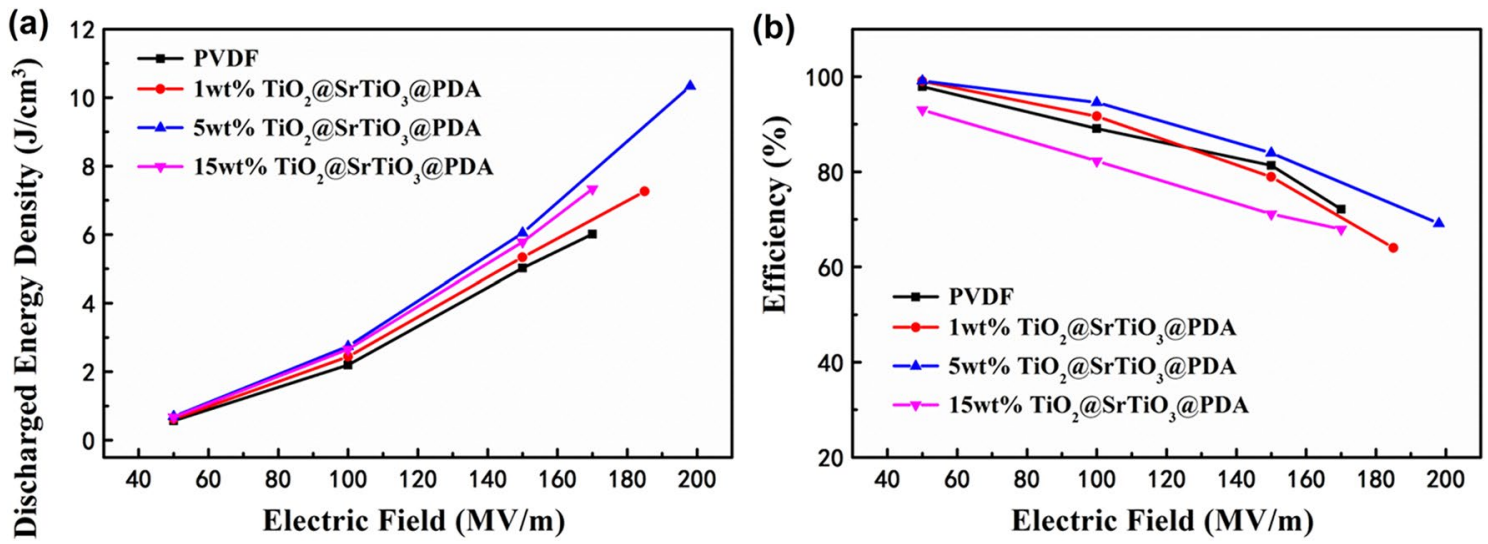

Figure 11. (a) Discharged energy densities and (b) charge-discharge efficiencies of PVDF-based NCs with different weight fractions of $\mathrm{TiO}_{2} @ \mathrm{SrTiO}_{3} @ \mathrm{PDA}$ NWs. This figure was created using OriginLab OriginPro 8.5 (https://www.originlab.com) and Microsoft Office PowerPoint 2007 (https://www.office.com).

\begin{tabular}{|c|c|c|c|c|c|}
\hline Matrix & Fillers & Sample thickness $(\mu \mathrm{m})$ & $\mathrm{E}_{\mathrm{b}}(\mathrm{MV} / \mathrm{m})$ & $\mathrm{U}_{\text {dis }}\left(\mathrm{J} / \mathrm{cm}^{3}\right)$ & Refs. \\
\hline PVDF & $\mathrm{BaTiO}_{3} @ \mathrm{Al}_{2} \mathrm{O}_{3} \mathrm{nps}$ & $\sim 10$ & 280 & 6.1 & 47 \\
\hline PVDF & $\mathrm{BaTiO}_{3} @ \mathrm{SiO}_{2} \mathrm{nps}$ & $12-30$ & 420 & 11.5 & 48 \\
\hline PVDF & TO@BT nps & 10 & 380 & 8.78 & 49 \\
\hline PVDF & $\mathrm{BaTiO}_{3} @ \mathrm{Al}_{2} \mathrm{O}_{3} \mathrm{nfs}$ & $10-15$ & 380 & 7.1 & 50 \\
\hline PVDF & BT@AO-DA NFs & $\sim 10$ & 420 & 10.58 & 51 \\
\hline PVDF & $\mathrm{BaTiO}_{3} @ \mathrm{Al}_{2} \mathrm{O}_{3} \mathrm{nfs}$ & $\sim 10$ & 400 & 12.18 & 52 \\
\hline PVDF & $\mathrm{TiO}_{2}-\mathrm{BT}-\mathrm{TiO}_{2} @$ dopa & $1-3$ & 312.8 & 4.4 & \begin{tabular}{|l|l|}
53 \\
\end{tabular} \\
\hline PVDF & $\mathrm{BaTiO}_{3} / \mathrm{SiO}_{2}$ nps & $10-30$ & 340 & 6.28 & 54 \\
\hline P(VDF-TrFE-CTFE) & $\mathrm{TiO}_{2} @ \mathrm{PZT}$ & $\sim 7$ & 143 & 6.9 & 16 \\
\hline P(VDF-TrFE) & $\mathrm{BaSrTiO}_{3}$ & $30-40$ & 155 & 4.72 & 55 \\
\hline $\mathrm{P}$ (VDF-HFP) & TO-450 NFs & $\sim 50$ & 160 & 7.63 & 56 \\
\hline PVDF & CCTO@ $\mathrm{Al}_{2} \mathrm{O}_{3} \mathrm{NFs}$ & $\sim 15$ & 340 & 8.46 & 57 \\
\hline PVDF & $\mathrm{TiO}_{2} @ \mathrm{SrTiO}_{3} @ \mathrm{PDA}$ & $\sim 50$ & 198 & 10.34 & \begin{tabular}{|l} 
This work \\
\end{tabular} \\
\hline
\end{tabular}

Table 2. Summary of the discharge energy density for various dielectric NCs containing different fillers. Nanoparticles (nps); Nanofibres (nfs); $\mathrm{BaTiO}_{3} @ \mathrm{Al}_{2} \mathrm{O}_{3}$-dopamine (BT@AO-DA); $\mathrm{TiO}_{2}-\mathrm{BaTiO}_{3}-\mathrm{TiO}_{2} @$ dopamine $\left(\mathrm{TiO}_{2}-\mathrm{BT}-\mathrm{TiO}_{2} @ \mathrm{dopa}\right) ; \mathrm{TiO}_{2} @ \mathrm{~Pb}\left(\mathrm{Zr}_{11 \mathrm{x}} \mathrm{Ti}_{\mathrm{x}}\right) \mathrm{O}_{3}\left(\mathrm{TiO}_{2} @ \mathrm{PZT}\right) ; \mathrm{CaCu}_{3} \mathrm{Ti}_{4} \mathrm{O}_{12}(\mathrm{CCTO})$.

surface-modified $\mathrm{TiO}_{2} @ \mathrm{SrTiO}_{3} \mathrm{NWs}$ is above $95 \%$ below $100 \mathrm{MV} / \mathrm{m}$, and remains at $69 \%$ at $198 \mathrm{MV} / \mathrm{m}$. Moreover, when the applied electric field increases, the efficiency of all NCs decreases due to the conduction loss.

To understand the impact of $\mathrm{SrTiO}_{3}$ shell upon the energy storage capability, the energy density and charge-discharge efficiency of the NCs with 15 wt\% TiO ${ }_{2} @ S_{r T i O} @ P D A N W s, S_{3} \mathrm{PiO}_{3} @ P D A$ NWs and TiO $@$ PDA NWs were analyzed. The D-E loops of the 15 wt\% TiO @SrTiO $_{3} @ P D A ~ N W s / P V D F ~ N C, 15 w t \% S_{3} T i O_{3} @$ PDA NWs/PVDF NC and the 15 wt\% TiO $@ P D A$ NWs/PVDF NC were measured at $100 \mathrm{~Hz}$ as displayed in Figs. S4d and S7. Compared with the $15 \mathrm{wt} \% \mathrm{SrTiO}_{3} @ P D A$ NWs/PVDF NC and $15 \mathrm{wt} \% \mathrm{TiO}_{2} @ \mathrm{PDA}$ NWs/PVDF $\mathrm{NC}$, the $15 \mathrm{wt} \% \mathrm{TiO}_{2} @ \mathrm{SrTiO}_{3} @ \mathrm{PDA} \mathrm{NWs} / \mathrm{PVDF} \mathrm{NC}$ has a higher maximum electric displacement under the same electric fields (Fig. S8a), due to the additional interfacial polarization within the core-shell structure nanofillers. The charged and discharge energy density of the NC with 15 wt \% TiO $@ \mathrm{SrTiO}_{3} @ \mathrm{PDA} \mathrm{NWs}$ are higher than those of NC with 15 wt\% $\mathrm{SrTiO}_{3} @ \mathrm{PDA}$ NWs and NC with 15 wt\% $\mathrm{TiO}_{2} @ \mathrm{PDA}$ NWs, as displayed in Fig. S9 and 12a. The NC with 15 wt\% $\mathrm{TiO}_{2} @ \mathrm{SrTiO}_{3} @ \mathrm{PDA}$ NWs exhibits the superior discharge energy densities equal to $7.33 \mathrm{~J} / \mathrm{cm}^{3}$ (at $170 \mathrm{MV} / \mathrm{m}$ ), which is higher than discharge energy densities of the $15 \mathrm{wt} \% \mathrm{SrTiO}_{3} @ \mathrm{PDA} \mathrm{NWs} /$ PVDF NC and $15 \mathrm{wt} \% \mathrm{TiO}_{2} @ P D A$ NWs/PVDF NC (i.e. $5.60 \mathrm{~J} / \mathrm{cm}^{3}$ at $150 \mathrm{MV} / \mathrm{m}$ and $6.25 \mathrm{~J} / \mathrm{cm}^{3}$ at $165 \mathrm{MV} / \mathrm{m}$, respectively). Compared to the $15 \mathrm{wt} \% \mathrm{SrTiO}_{3} @ \mathrm{PDA} \mathrm{NW} / \mathrm{PVDF} \mathrm{NC}$ and $15 \mathrm{wt} \% \mathrm{TiO}_{2} @ \mathrm{PDA} \mathrm{NWs} / \mathrm{PVDF}$ $\mathrm{NC}$, the 15 wt\% TiO $@ \mathrm{SrTiO}_{3} @ \mathrm{PDA} \mathrm{NWs} / \mathrm{PVDF} \mathrm{NC}$ has a higher effective electric displacement $\left(\mathrm{D}_{\max }-\mathrm{D}_{\mathrm{r}}\right)$ and higher breakdown strength (Fig. S8b and 9), both of which contribute to the enhancement of the discharge energy density. Moreover, the 15 wt\% $\mathrm{TiO}_{2} @ \mathrm{SrTiO}_{3} @ \mathrm{PDA}$ NWs/PVDF NC film has a higher charge-discharge efficiency than the $15 \mathrm{wt} \% \mathrm{SrTiO}_{3} @ \mathrm{PDA}$ NWs/PVDF NC film and $15 \mathrm{wt} \% \mathrm{TiO}_{2} @ P D A$ NWs/PVDF NC film as shown in Fig. 12b. These results indicate that the core-shell structured $\mathrm{TiO}_{2} @ \mathrm{SrTiO}_{3} @ \mathrm{PDA} \mathrm{NWs}$ are beneficial for the improvement of the energy storage performance of NCs. 

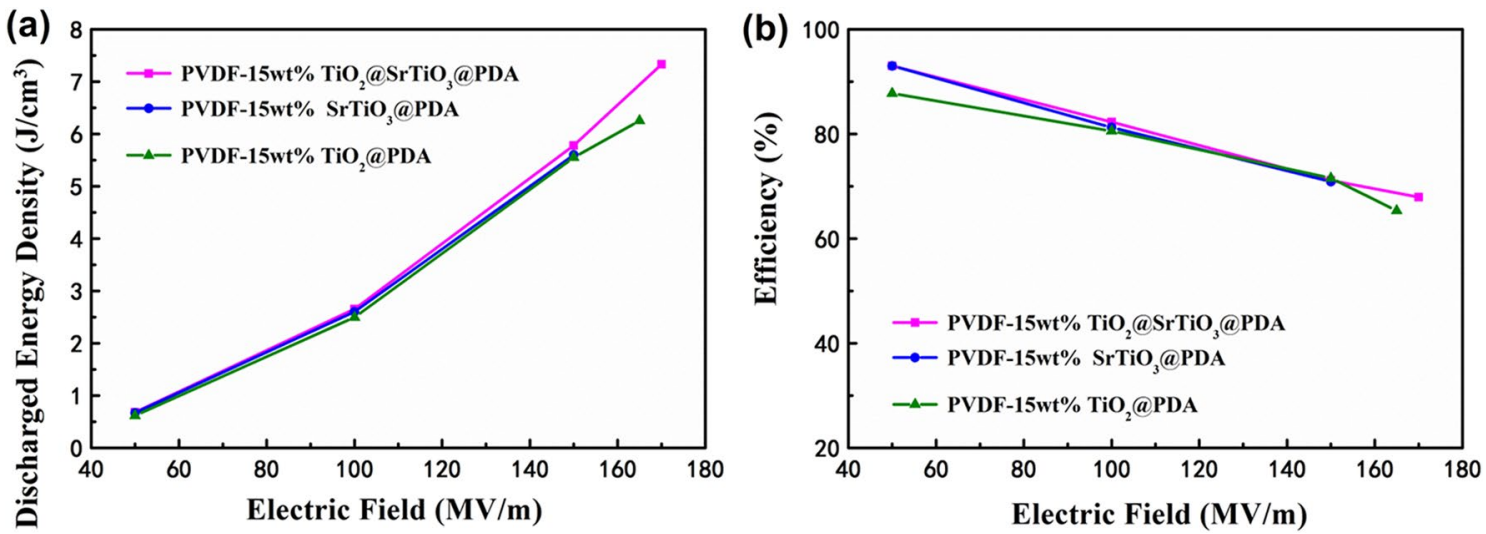

Figure 12. (a) Discharged energy densities and (b) charge-discharge efficiencies of $\mathrm{TiO}_{2} @ \mathrm{SrTiO}_{3} @ \mathrm{PDA} \mathrm{NWs/}$ PVDF NC, $\mathrm{SrTiO}_{3} @ P D A$ NWs/PVDF NC and $\mathrm{TiO}_{2} @ P D A ~ N W s / P V D F ~ N C$ with 15 wt $\%$ of fillers. This figure was created using OriginLab OriginPro 8.5 (https://www.originlab.com) and Microsoft Office PowerPoint 2007 (https://www.office.com).



Figure 13. The stress-strain curves for the pristine PVDF and $5 \mathrm{wt} \% \mathrm{TiO}_{2} @ \mathrm{SrTiO}_{3} @ \mathrm{PDA} \mathrm{NWs} / \mathrm{PVDF} \mathrm{NC}$ at room temperature. This figure was created using OriginLab OriginPro 8.5 (https://www.originlab.com).

Mechanical properties of $\mathrm{TiO}_{2} @ \mathrm{SrTiO}_{3} @ P D A$ NWs/PVDF nanocomposites. The mechanical properties of the NC films are an important parameter for practical applications. The mechanical properties of PVDF and 5 wt\% TiO $@ \mathrm{SrTiO}_{3} @ P D A$ NWs/PVDF NC with excellent energy storage performance were investigated. Figure 13 shows the stress and strain curves of PVDF and the $5 \mathrm{wt} \% \mathrm{TiO}_{2} @ \mathrm{SrTiO}_{3} @ \mathrm{PDA} \mathrm{NWs} / \mathrm{PVDF}$ NC. The elongation at break of the $5 \mathrm{wt} \% \mathrm{TiO}_{2} @ \mathrm{SrTiO}_{3} @ \mathrm{PDA} \mathrm{NWs} / \mathrm{PVDF} \mathrm{NC}$ is lower than that of pristine PVDF. There are two factors that explain this phenomenon. First, the $\mathrm{TiO}_{2} @ \mathrm{SrTiO}_{3} @ \mathrm{PDA} \mathrm{NWs}$ can act as stress concentrators, providing the potential crack growth sites of the NCs. Second, the nanofillers can serve as physical obstacles that block the motion of polymer chains, leading to a brittle fracture ${ }^{58}$. Compared to pure PVDF, the $5 \mathrm{wt} \% \mathrm{TiO}_{2} @ \mathrm{SrTiO}_{3} @ \mathrm{PDA} \mathrm{NWs} / \mathrm{PVDF} \mathrm{NC}$ film has a larger tensile strength and tensile modulus due to the introduction of $\mathrm{TiO}_{2} @ \mathrm{SrTiO}_{3} @ \mathrm{PDA}$ NWs. As shown in Fig. 13, the tensile strength and tensile modulus of the $\mathrm{NC}$ with 5 wt\% surface-modified $\mathrm{TiO}_{2} @ \mathrm{SrTiO}_{3} \mathrm{NWs}$ are $49.8 \mathrm{MPa}$ and $1560 \mathrm{MPa}$, respectively, which are larger than those of pure PVDF (i.e. tensile strength of $47.6 \mathrm{MPa}$ and tensile modulus of $1200 \mathrm{MPa}$ ). The researches show that the larger tensile modulus is, the higher the breakdown field is. Therefore, the increased tensile modulus is beneficial for the enhancement of discharged energy density in the $\mathrm{NCs}^{59,60}$.

\section{Conclusions}

In this work, the NCs consisting of PVDF and functionalized $\mathrm{TiO}_{2} @ \mathrm{SrTiO}_{3} \mathrm{NWs}$ were fabricated by the solution casting technique. To improve the distributional homogeneity and compatibility between the nanofillers and PVDF matrix, the $\mathrm{TiO}_{2} @ \mathrm{SrTiO}_{3} \mathrm{NWs}$ were modified by dopamine. Thanks to the well-designed hierarchical interfacial polarization among their multiple interfaces, the large aspect ratio as well as surface modification of the $\mathrm{TiO}_{2} @ \mathrm{SrTiO}_{3} \mathrm{NWs}$, the breakdown strength and electric displacement are simultaneously enhanced by incorporation of a small amount of $\mathrm{TiO}_{2} @ \mathrm{SrTiO}_{3} @ \mathrm{PDA} \mathrm{NWs}$, giving rise to high energy density of $\mathrm{TiO}_{2} @$ 
$\mathrm{SrTiO}_{3} @ \mathrm{PDA} / \mathrm{PVDF}$ NCs. As a result, the maximum discharge energy density equal to $10.34 \mathrm{~J} / \mathrm{cm}^{3}$ was achieved for the NC film containing 5 wt\% TiO $\mathrm{TSrTiO}_{3} @ \mathrm{PDA} \mathrm{NWs}$ at $198 \mathrm{MV} / \mathrm{m}$, which is larger than the value for pure PVDF (i.e. $6.01 \mathrm{~J} / \mathrm{cm}^{3}$ at $170 \mathrm{MV} / \mathrm{m}$ ). Due to the introduction of $\mathrm{TiO}_{2} @ \mathrm{SrTiO}_{3} @ \mathrm{PDA} \mathrm{NWs}$, the tensile strength and modulus of the NC film are larger than those of pure PVDF. The results presented herein provide a good approach for the design the NC films with high energy storage capability and good mechanical properties.

Received: 28 March 2020; Accepted: 5 August 2020

Published online: 13 October 2020

\section{References}

1. Zhang, D., Liu, W., Tang, L., Zhou, K. \& Luo, H. High performance capacitors via aligned $\mathrm{TiO}_{2}$ nanowire array. Appl. Phys. Lett. 110, 133902 (2017).

2. Wang, Y. et al. Compositional tailoring effect on electric field distribution for significantly enhanced breakdown strength and restrained conductive loss in sandwich-structured ceramic/polymer nanocomposites. J. Mater. Chem. A 5, 4710-4718 (2017).

3. Kang, D., Wang, G., Huang, Y., Jiang, P. \& Huang, X. Decorating $\mathrm{TiO}_{2}$ nanowires with $\mathrm{BaTiO}_{3}$ nanoparticles: A new approach leading to substantially enhanced energy storage capability of high-k polymer nanocomposites. ACS Appl. Mater. Interfaces 10, 4077-4085 (2018).

4. Wang, G., Huang, X. \& Jiang, P. Mussel-inspired fluoro-polydopamine functionalization of titanium dioxide nanowires for polymer nanocomposites with significantly enhanced energy storage capability. Sci. Rep. 7, 43071 (2017).

5. Chen, S.-S. et al. Enhanced breakdown strength and energy density in PVDF nanocomposites with functionalized MgO nanoparticles. RSC Adv. 6, 33599-33605 (2016).

6. Liao, S. et al. Surface-modified $\mathrm{TiO}_{2}$ nanorod array/P(VDF-HFP) dielectric capacitor with ultra high energy density and efficiency. J. Mater. Chem. C 5, 12777-12784 (2017).

7. Shen, Z.-H. et al. High-throughput phase-field design of high-energy-density polymer nanocomposites. Adv. Mater. 30, 1704380 (2018).

8. Yao, L., Pan, Z., Liu, S., Zhai, J. \& Chen, H. H. Significantly enhanced energy density in nanocomposite capacitors combining the $\mathrm{TiO}_{2}$ nanorod array with poly(vinylidene fluoride). ACS Appl. Mater. Interfaces 8, 26343-26351 (2016).

9. Wang, Y. et al. Significantly enhanced breakdown strength and energy density in sandwich-structured barium titanate/ poly(vinylidene fluoride) nanocomposites. Adv. Mater. 27, 6658-6663 (2015).

10. Wang, J. et al. Improving dielectric properties and energy storage performance of poly(vinylidene fluoride) nanocomposite by surface-modified $\mathrm{SrTiO}_{3}$ nanoparticles. J. Alloys Compd. 726, 587-592 (2017).

11. Zhang, D. et al. High performance capacitors using $\mathrm{BaTiO}_{3}$ nanowires engineered by rigid liquid-crystalline polymers. J. Phys. Chem. C 121, 20075-20083 (2017).

12. Luo, H. et al. Enhancement of dielectric properties and energy storage density in poly(vinylidene fluoride-co-hexafluoropropylene) by relaxor ferroelectric ceramics. RSC Adv. 5, 68515-68522 (2015).

13. Chen, Q., Shen, Y., Zhang, S. \& Zhang, Q. M. Polymer-based dielectrics with high energy storage density. Annu. Rev. Mater. Res. 45, 433-458 (2015).

14. Prateek, Thakur, V. K. \& Gupta, R. K. Recent progress on ferroelectric polymer-based nanocomposites for high energy density capacitors: synthesis, dielectric properties, and future aspects. Chem. Rev. 116, 4260-4317 (2016).

15. Yao, L. et al. High-energy-density with polymer nanocomposites containing of $\mathrm{SrTiO}_{3}$ nanofibers for capacitor application. Compos. A Appl. Sci. Manuf. 109, 48-54 (2018).

16. Zhang, D., Liu, W., Guo, R., Zhou, K. \& Luo, H. High discharge energy density at low electric field using an aligned titanium dioxide/lead zirconate titanate nanowire array. Adv. Sci. 5, 1700512 (2017).

17. Luo, H. et al. Highly enhanced dielectric strength and energy storage density in hydantoin@ $\mathrm{BaTiO}_{3}-\mathrm{P}(\mathrm{VDF}-\mathrm{HFP})$ composites with a sandwich-structure. RSC Adv. 5, 52809-52816 (2015).

18. Luo, H. et al. Enhanced performance of $\mathrm{P}(\mathrm{VDF}-\mathrm{HFP})$ composites using two-dimensional $\mathrm{BaTiO}_{3}$ platelets and graphene hybrids. Compos. Sci. Technol. 160, 237-244 (2018).

19. Kim, P. et al. Phosphonic acid-modified barium titanate polymer nanocomposites with high permittivity and dielectric strength. Adv. Mater. 19, 1001-1005 (2007).

20. Yao, L., Pan, Z., Zhai, J. \& Chen, H. H. Novel design of highly [110]-oriented barium titanate nanorod array and its application in nanocomposite capacitors. Nanoscale 9, 4255-4264 (2017).

21. Pan, Z., Yao, L., Zhai, J., Shen, B. \& Wang, H. Significantly improved dielectric properties and energy density of polymer nanocomposites via small loaded of $\mathrm{BaTiO}_{3}$ nanotubes. Compos. Sci. Technol. 147, 30-38 (2017).

22. Liu, S. et al. Poly(vinylidene fluoride) nanocomposite capacitors with a significantly enhanced dielectric constant and energy density by filling with surface-fluorinated $\mathrm{Ba}_{0.6} \mathrm{Sr}_{0.4} \mathrm{TiO}_{3}$ nanofibers. RSC Adv. 5, 40692-40699 (2015).

23. Tang, $\mathrm{H}$. \& Sodano, H. A. Ultra high energy density nanocomposite capacitors with fast discharge using $\mathrm{Ba}_{0.2} \mathrm{Sr}_{0.8} \mathrm{TiO}_{3}$ nanowires. Nano Lett. 13, 1373-1379 (2013).

24. Liu, S. \& Zhai, J. Improving the dielectric constant and energy density of poly(vinylidene fluoride) composites induced by surfacemodified $\mathrm{SrTiO}_{3}$ nanofibers by polyvinylpyrrolidone. J. Mater. Chem. A 3, 1511-1517 (2015).

25. Zhang, X. et al. Giant energy density and improved discharge efficiency of solution-processed polymer nanocomposites for dielectric energy storage. Adv. Mater. 28, 2055-2061 (2016).

26. Zhang, X. et al. Ultrahigh energy density of polymer nanocomposites containing $\mathrm{BaTiO}_{3} @ \mathrm{TiO}_{2}$ nanofibers by atomic-scale interface engineering. Adv. Mater. 27, 819-824 (2015).

27. Pan, Z. et al. Largely enhanced energy storage capability of a polymer nanocomposite utilizing a core-satellite strategy. Nanoscale 10, 16621-16629 (2018).

28. Wang, G., Huang, X. \& Jiang, P. tailoring dielectric properties and energy density of ferroelectric polymer nanocomposites by high-k nanowires. ACS Appl. Mater. Interfaces 7, 18017-18027 (2015).

29. Park, K. I. et al. Lead-free $\mathrm{BaTiO}_{3}$ nanowires-based flexible nanocomposite generator. Nanoscale 6, 8962-8968 (2014).

30. Tang, H. \& Sodano, H. A. High energy density nanocomposite capacitors using non-ferroelectric nanowires. Appl. Phys. Lett. 102, 063901 (2013).

31. Cao, T., Li, Y., Wang, C., Shao, C. \& Liu, Y. A facile in situ hydrothermal method to $\mathrm{SrTiO}_{3} / \mathrm{TiO}_{2}$ nanofiber heterostructures with high photocatalytic activity. Langmuir ACS J. Surf. Colloids 27, 2946-2952 (2011).

32. Lee, H., Scherer, N. F. \& Messersmith, P. B. Single-molecule mechanics of mussel adhesion. Proc. Natl. Acad. Sci. 103, 12999-13003 (2006).

33. Lee, H., Dellatore, S. M., Miller, W. M. \& Messersmith, P. B. Mussel-inspired surface chemistry for multifunctional coatings. Science 318, 426-430 (2007) 
34. Lee, H. et al. Substrate-independent layer-by-layer assembly by using mussel-adhesive-inspired polymers. Adv. Mater. 20, 1619$1623(2008)$.

35. Li, Y., Liu, M., Xiang, C., Xie, Q. \& Yao, S. Electrochemical quartz crystal microbalance study on growth and property of the polymer deposit at gold electrodes during oxidation of dopamine in aqueous solutions. Thin Solid Films 497, 270-278 (2006).

36. Pan, Z., Zhai, J. \& Shen, B. Multilayer hierarchical interfaces with high energy density in polymer nanocomposites composed of $\mathrm{BaTiO}_{3} @ \mathrm{TiO}_{2} @ \mathrm{Al}_{2} \mathrm{O}_{3}$ nanofibers. J. Mater.Chem.A 5, 15217-15226 (2017).

37. Boccaccio, T., Bottino, A., Capannelli, G. \& Piaggio, P. Characterization of PVDF membranes by vibrational spectroscopy. J. Membr. Sci. 210, 315-329 (2002).

38. Li, W. et al. Electric energy storage properties of poly(vinylidene fluoride). Appl. Phys. Lett. 96, 192905 (2010).

39. Xu, N., Zhang, Q., Yang, H., Xia, Y. \& Jiang, Y. In-situ preparation of hierarchical flower-like $\mathrm{TiO}_{2} /$ carbon nanostructures as fillers for polymer composites with enhanced dielectric properties. Sci. Rep. 7, 43970 (2017).

40. Li, W. et al. Largely enhanced dielectric and thermal conductive properties of novel ternary composites with small amount of nanofillers. Compos. Sci. Technol. 163, 71-80 (2018).

41. Liu, S., Xue, S., Xiu, S., Shen, B. \& Zhai, J. Surface-modified $\mathrm{Ba}\left(\mathrm{Zr}_{0.3} \mathrm{Ti}_{0.7}\right) \mathrm{O}_{3}$ nanofibers by polyvinylpyrrolidone filler for poly(vinylidene fluoride) composites with enhanced dielectric constant and energy storage density. Sci. Rep. 6, 26198 (2016).

42. Liu, S., Xue, S., Zhang, W. \& Zhai, J. Enhanced dielectric and energy storage density induced by surface-modified $\mathrm{BaTiO}_{3}$ nanofibers in poly(vinylidene fluoride) nanocomposites. Ceram. Int. 40, 15633-15640 (2014).

43. Pan, Z. et al. Highly enhanced discharged energy density of polymer nanocomposites via a novel hybrid structure as fillers. J. Mater. Chem. A 7, 15347-15355 (2019).

44. Yue, X., Zhang, J., Yan, F., Wang, X. \& Huang, F. A situ hydrothermal synthesis of $\mathrm{SrTiO}_{3} / \mathrm{TiO}_{2}$ heterostructure nanosheets with exposed (001) facets for enhancing photocatalytic degradation activity. Appl. Surf. Sci. 319, 68-74 (2014).

45. Wang, Y. et al. Ultrahigh electric displacement and energy density in gradient layer-structured $\mathrm{BaTiO}_{3} / \mathrm{PVDF}$ nanocomposites with an interfacial barrier effect. J. Mater. Chem. A 5, 10849-10855 (2017).

46. Hou, Y., Deng, Y., Wang, Y. \& Gao, H. Uniform distribution of low content $\mathrm{BaTiO}_{3}$ nanoparticles in poly(vinylidene fluoride) nanocomposite: Toward high dielectric breakdown strength and energy storage density. RSC Adv. 5, 72090-72098 (2015).

47. Liu, S., Wang, J., Hao, H., Zhao, L. \& Zhai, J. Discharged energy density and efficiency of nanocomposites based on poly(vinylidene fluoride) and core-shell structured $\mathrm{BaTiO}_{3} @ \mathrm{Al}_{2} \mathrm{O}_{3}$ nanoparticles. Ceram. Int. 44, 22850-22855 (2018).

48. Bi, K. et al. Ultrafine core-shell $\mathrm{BaTiO}_{3} @ \mathrm{SiO}_{2}$ structures for nanocomposite capacitors with high energy density. Nano Energy 51, 513-523 (2018).

49. Hu, P., Jia, Z., Shen, Z., Wang, P. \& Liu, X. High dielectric constant and energy density induced by the tunable $\mathrm{TiO}_{2}$ interfacial buffer layer in PVDF nanocomposite contained with core-shell structured $\mathrm{TiO}_{2} @ \mathrm{BaTiO}_{3}$ nanoparticles. Appl. Surf. Sci. 441, 824-831 (2018).

50. Liu S. et al. Poly(vinylidene fluoride) nanocomposites with a small loading of core-shell structured $\mathrm{BaTiO}_{3} @ \mathrm{Al}_{2} \mathrm{O}_{3}$ nanofibers exhibiting high discharged energy density and efficiency. J. Alloys Compd. (2016).

51. Pan, Z. et al. High-energy-density polymer nanocomposites composed of newly structured one-dimensional $\mathrm{BaTiO}_{3} @ \mathrm{Al}_{2} \mathrm{O}_{3}$ nanofibers. ACS Appl. Mater. Interfaces 9, 4024-4033 (2017).

52. Pan, Z. et al. Excellent energy density of polymer nanocomposites containing $\mathrm{BaTiO}_{3} @ \mathrm{Al}_{2} \mathrm{O}_{3}$ nanofibers induced by moderate interfacial area. J. Mater. Chem. A 4, 13259-13264 (2016).

53. Prateek, R., Bhunia, R., Siddiqui, S., Garg, A. \& Gupta, R. K. Significantly enhanced energy density by tailoring the interface in hierarchically structured $\mathrm{TiO}_{2}-\mathrm{BaTiO}_{3}-\mathrm{TiO}_{2}$ nanofillers in PVDF-based thin-film polymer nanocomposites. ACS Appl. Mater. Interfaces 11, 14329-14339 (2019).

54. Yu, K., Niu, Y., Bai, Y., Zhou, Y. \& Wang, H. Poly(vinylidene fluoride) polymer based nanocomposites with significantly reduced energy loss by filling with core-shell structured $\mathrm{BaTiO}_{3} / \mathrm{SiO}_{2}$ nanoparticles. Appl. Phys. Lett. 102, 102903 (2013).

55. $\mathrm{Hu}$, P. et al. Largely enhanced energy density in flexible $\mathrm{P}(\mathrm{VDF}-\mathrm{TrFE})$ nanocomposites by surface-modified electrospun $\mathrm{BaSrTiO}_{3}$ fibers. J. Mater. Chem. A 1, 1688-1693 (2013).

56. Chu, H. et al. Carbon-doped inorganic nanoassemblies as fillers to tailor the dielectric and energy storage properties in polymerbased nanocomposites. Mater. Des. 188, 108486 (2020).

57. Chi, Q. et al. High energy storage density for poly(vinylidene fluoride) composites by introduced core-shell $\mathrm{CaCu}_{3} \mathrm{Ti}_{4} \mathrm{O}_{12} @ \mathrm{Al}_{2} \mathrm{O}_{3}$ nanofibers. ACS Sustain. Chem. Eng. 6, 8641-8649 (2018).

58. $\mathrm{Xu}$, S. et al. Structure and properties of electrically conducting composites consisting of alternating layers of pure polypropylene and polypropylene with a carbon black filler. Polymer 49, 4861-4870 (2008).

59. Shen, Y. et al. Enhanced breakdown strength and suppressed leakage current of polyvinylidene fluoride nanocomposites by twodimensional $\mathrm{ZrO}_{2}$ nanosheets. Mater. Express 6, 277-282 (2016).

60. Xie, Y., Yu, Y., Feng, Y., Jiang, W. \& Zhang, Z. Fabrication of stretchable nanocomposites with high energy density and low loss from cross-linked PVDF filled with poly(dopamine) encapsulated $\mathrm{BaTiO}_{3}$. ACS Appl. Mater. Interfaces 9, 2995-3005 (2017).

\section{Acknowledgements}

This research did not receive any specific grant from funding agencies of the public, commercial, or non-profit sectors.

\section{Author contributions}

J. X. designed the study, prepared and characterized samples, and wrote the manuscripts. C. F. and H.C. discussed the results. All authors reviewed the manuscript. All the figures were drawn by J. X.

\section{Competing interests}

The authors declare no competing interests.

\section{Additional information}

Supplementary information is available for this paper at https://doi.org/10.1038/s41598-020-73884-6.

Correspondence and requests for materials should be addressed to X.R. or W.N.

Reprints and permissions information is available at www.nature.com/reprints.

Publisher's note Springer Nature remains neutral with regard to jurisdictional claims in published maps and institutional affiliations. 
(c) (i) Open Access This article is licensed under a Creative Commons Attribution 4.0 International cc) License, which permits use, sharing, adaptation, distribution and reproduction in any medium or format, as long as you give appropriate credit to the original author(s) and the source, provide a link to the Creative Commons licence, and indicate if changes were made. The images or other third party material in this article are included in the article's Creative Commons licence, unless indicated otherwise in a credit line to the material. If material is not included in the article's Creative Commons licence and your intended use is not permitted by statutory regulation or exceeds the permitted use, you will need to obtain permission directly from the copyright holder. To view a copy of this licence, visit http://creativecommons.org/licenses/by/4.0/.

(C) The Author(s) 2020 